\title{
Autoempleo agropecuario, redes sociales e inclusión de sujetos vulnerables: Un estudio de cuatro distritos de la región pampeana argentina ${ }^{1}$
}

\author{
Clara Craviotti, CONICET, Argentina²
}

\begin{abstract}
Resumen
Este artículo analiza la incidencia de las redes sociales en situaciones de inicio de emprendimientos agropecuarios en pequeña escala como alternativa laboral frente a las dificultades experimentadas en el mercado de trabajo. Lo hace desde dos puntos de vista: como forma de acceso a diferentes bienes y servicios, y como mecanismos de construcción de identidad. Para ello se examina el contenido de dichas relaciones (alrededor de ciertos ejes como son la cooperación, la confianza, el conflicto), así como su carácter (simétrico/asimétrico), en función de las (posibles) disparidades de recursos entre los sujetos involucrados. Emplea para ello una estrategia metodológica que combina fuentes y técnicas de análisis cuanti y cualitativas, si bien otorga énfasis a éstas últimas, para lo cual se basa en entrevistas a informantes calificados a nivel nacional vinculados a diferentes programas de apoyo a microemprendimientos, entrevistas a sujetos vulnerables que iniciaron actividades por cuenta propia en el ámbito agropecuario y a otros que las abandonaron luego de iniciadas, así como informantes clave pertenecientes a diversas organizaciones locales.
\end{abstract}

Palabras clave: Autoempleo- Vulnerabilidad- Desarrollo local -

\begin{abstract}
This article analyzes the incidence of social networks in the beginning of agricultural micro enterprises as a work alternative, in face of the difficulties experienced at the labor market. It considers these networks from two different points of view: as a way of access to different goods and services, and as mechanisms of identity construction. It examines the content of these relationships (around certain axes such as cooperation, trust and conflict), as well as their symmetric /asymmetric character, taking into account (possible) disparities of resources among those involved in them. It employs a methodological strategy that combines quantitative and qualitative sources and techniques of analysis, although it gives emphasis to the latter. For these purposes interviews with qualified informants at the national level linked to different support programs were carried out, as well as interviews with vulnerable people that began self-employed activities in agriculture, and with others that abandoned them after initiated, and to key informants belonging to different types of organizations at the local level.
\end{abstract}

Key words: Self employment - Vulnerability - Local development.

\footnotetext{
${ }^{1}$ Este artículo se inscribe en el marco del proyecto de investigación "La incorporación a la producción agropecuaria de sujetos en situación de vulnerabilidad social. Trayectorias y modalidades de inserción", financiado por la Agencia Nacional de Promoción Científica y Tecnológica, Argentina.

2 Lic. en Sociología, Master en Ciencias Sociales con mención en Estudios Agrarios; Dra. en Geografía. Investigadora del Consejo Nacional de Investigaciones Científicas y Técnicas (CONICET) y Profesora de la Maestría de Estudios Sociales Agrarios (FLACSO), Argentina / Email: ccraviotti@yahoo.com
} 
Las condiciones que facilitan el surgimiento y consolidación de las actividades por cuenta propia han despertado el interés de los investigadores desde diversas disciplinas, ya sea como mecanismo de generación de ingresos familiares en poblaciones con dificultades para insertarse en el mercado de trabajo, o como canal de innovación y disparador de procesos de desarrollo local, para mencionar algunas perspectivas no necesariamente contrapuestas. En ese marco se ha destacado la importancia de las características personales (conocimientos y experiencia previa en la actividad, motivaciones, "espíritu emprendedor"), aunque crecientemente se remite a los aspectos contextuales que posibilitan estos desarrollos. Se incluyen aquí rasgos más definidamente culturales -el valor otorgado a las actividades autónomas en un contexto social determinado- hasta la existencia de mecanismos de cooperación entre los actores o bien de instrumentos de apoyo (crédito, capacitación, asesoramiento técnico, etc.) que operan, directa o indirectamente, como incubadores de "nuevos" emprendimientos.

Es posible suponer que algunos de estos factores son particularmente críticos en sujetos que inician una actividad independiente para producir los ingresos necesarios para su subsistencia. Es decir, se puede conjeturar que en estos casos las posibilidades de inserción estable dependerán en buena medida de la amplitud y variedad de redes sociales y apoyos institucionales a los que acceden, así como del contexto de oportunidades existente - particularmente la conexión de las actividades iniciadas con aquellas que son la base de las economías de los distritos-. El carácter que asumen las redes sociales incidirá también en los procesos de construcción identitaria que experimentan estos sujetos, conjuntamente con otros factores -como las trayectorias ocupacionales previas y la importancia de las actividades desempeñadas en los ingresos y en las modalidades de asignación del trabajo.

Es pertinente destacar que la Argentina presenta particularidades propias, en el sentido de que las actividades autónomas han desempeñado, quizás, un papel menos dinámico como amortiguador o "válvula de escape" frente al desempleo y la pobreza, en comparación con otros países latinoamericanos. Así, en el contexto del alto nivel de desempleo que caracterizó a la segunda mitad de los noventa, se constató en términos generales una pérdida de dinamismo del autoempleo, lo que agudizó la vulnerabilidad de amplios contingentes de trabajadores, sobre todo los de mediana edad y de bajos niveles educativos (Bayón, 2006). 
No obstante ello, trabajos previos (Craviotti, 2006) permitieron identificar situaciones de inicio de emprendimientos agropecuarios en pequeña escala como alternativa laboral frente a procesos de expulsión experimentados en el mercado de trabajo. Ello motivó el interés por profundizar en el conocimiento de estas situaciones, desarrollando una estrategia metodológica que combinara fuentes y técnicas de análisis cuanti y cualitativas. En ese marco se reprocesaron datos censales, se entrevistaron informantes calificados a nivel nacional vinculados a diferentes programas de apoyo a microemprendimientos, y se seleccionaron ámbitos locales para un análisis en profundidad. Dichos ámbitos, pertenecientes a la región pampeana argentina, presentan como características comunes una baja densidad poblacional, la importancia de las actividades agropecuarias dentro de la estructura del empleo, y una relativa distancia a ciudades grandes o intermedias. ${ }^{3}$ En ellos -cuatro en total- se entrevistaron sujetos vulnerables que iniciaron actividades productivas por cuenta propia en el ámbito agropecuario, otros que las abandonaron luego de iniciadas, así como informantes clave pertenecientes a ámbitos gubernamentales y organizaciones de representación de intereses a nivel local.

Partiendo de esta base, el objetivo del presente artículo consiste en analizar la incidencia de las redes sociales en los sujetos analizados desde dos puntos de vista: como forma de acceso a bienes y servicios diversos, y como mecanismos de construcción de identidad. Para ello se examina el contenido de dichas relaciones (alrededor de ciertos ejes como son la cooperación, la confianza, el conflicto), así como su carácter (simétrico/asimétrico), en función de las (posibles) disparidades de recursos entre los sujetos involucrados.

El foco del análisis son las redes egocéntricas, miradas desde la perspectiva de los individuos entrevistados, a partir de lo cual se procura, en una segunda instancia, extraer algunas implicancias desde el punto de vista de los espacios donde tales redes se asientan. Dado que se quiso captar la posible influencia de los procesos de reestructuración experimentados por los mercados de trabajo en los años noventa en el inicio de las actividades por cuenta propia, los casos seleccionados presentan una antigüedad como productores que no supera los ocho años. ${ }^{4}$ El análisis apunta

\footnotetext{
3 Si se toma el criterio de ruralidad considerado por el Instituto Nacional de Estadística y Censos (INDEC) de Argentina, algunas localidades serían clasificadas como urbanas, por superar los 2000 habitantes; si se consideran criterios de ruralidad ampliada, tal como propone el Banco Mundial (de Ferranti y otros, 2005) basándose en la Organización de Cooperación para el Desarrollo Económico (OCDE) - es decir, una densidad de población menor a los 150 habitantes por kilómetro cuadrado y una distancia a centros urbanos de más de 100.000 habitantes superior a la hora de viaje - claramente serían definidas como rurales.

4 Como criterios de selección para el estudio, se consideró que los emprendimientos debían estar orientados al mercado, en base al control de un capital relativamente reducido y en ellos el trabajo
} 
a reconstruir los entramados particulares de estos individuos, conectándolos con la situación de sus emprendimientos, aunque se reconoce que el tiempo transcurrido resulta relativamente escaso para evaluar su grado de consolidación como productores, y que, por las razones que se explicitan más abajo, las redes no pueden ser consideradas como "el" factor determinante de su evolución.

El artículo está estructurado en cuatro partes: Seguidamente se presenta una caracterización de los tipos de redes sociales según la intensidad de los vínculos desplegados y se analiza su expresión a nivel empírico en los casos estudiados. En el tercer apartado se profundiza en dichas redes como mecanismos de construcción identitaria, para finalizar con la consideración de algunas implicancias del análisis efectuado para el diseño de estrategias de intervención orientadas al apoyo de actividades por cuenta propia en sectores vulnerables.

\section{Tipos de vínculos e implicancias}

Teniendo en cuenta los aportes iniciales de Granovetter (1983), luego reformulados por otros autores (Woolcock, 2001; Robison y otros, 2003), desde el punto de vista de nuestra investigación, centrada en sujetos vulnerables que inician microemprendimientos agropecuarios destinados al mercado, resulta analíticamente útil preguntarse si el establecimiento de interacciones variadas contribuye a explicar su desempeño y contexto de oportunidades. Para ello partiremos de la siguiente diferenciación de los vínculos en función de su intensidad, sus fundamentos y la simetría de los sujetos involucrados en cuanto a acceso a recursos.

- Pueden caracterizarse como relaciones sociales de unión (a veces definido como bonding social capital) a las relaciones socialmente estrechas, generalmente basadas en puntos de coincidencia heredados o creados como resultado de compromisos para toda la vida y un contacto personal frecuente. Se caracterizan por intensos sentimientos de conexión, preocupación, afecto e interés por el otro.

propio y/o familiar debía tener centralidad para el desarrollo del proceso productivo. Se entrevistaron casos de apicultores, cunicultores, criadores de pollos parrilleros, productores hortícolas, entre otros. Asimismo, los casos debían haberse iniciado con posterioridad al año 2000 y presentar un mínimo de permanencia en la actividad - definido operativamente como haber comercializado su producción durante al menos una campaña -. Se consideró la índole de las ocupaciones desempeñadas por los sujetos con anterioridad al inicio del emprendimiento como criterio fundamental de vulnerabilidad. Más precisamente, su precariedad (dada por la carencia de estabilidad y/o de beneficios sociales) o su carácter no calificado, que se asocia con la percepción de ingresos bajos. No obstante en las entrevistas se identificaron otros indicadores, que corroboraron el carácter multidimensional del concepto y también la validez de la selección efectuada.

Los casos fueron seleccionados a partir de un "banco" de casos potenciales, relevado a partir de la consulta con diversos programas nacionales, organizaciones no gubernamentales, ámbitos municipales locales y referentes locales de organismos de asistencia técnica agropecuaria. Las entrevistas fueron grabadas, transcriptas y analizadas mediante el empleo del software Atlas ti. 
Por lo general se dan entre miembros de la familia y amigos cercanos; también entre los miembros de una minoría oprimida.

- Pueden definirse como relaciones sociales de vinculación (linking social capital) a los vínculos medianamente cercanos, que se apoyan en puntos de coincidencia adquiridos, a veces derivados de compromisos a mediano plazo. Se caracterizan por sentimientos moderadamente intensos de conexión, como la confianza y el compañerismo que pueden existir entre compañeros de trabajo o los miembros de un mismo club que comparten características similares.

- Por contraste, relaciones sociales de aproximación (bridging social capital) pueden darse entre personas que tienen pocos puntos de coincidencia, un contacto personal limitado y a menudo diferencias importantes en cuanto a los recursos que poseen. Estos vínculos involucran una dimensión vertical ausente en los tipos anteriores. $^{5}$

Como método analítico partimos de considerar la caracterización de las relaciones desde la perspectiva de los sujetos entrevistados, evitando el supuesto de que porque involucran determinadas contrapartes, de ello se deriva una intensidad determinada (el ejemplo más claro en este sentido son las relaciones familiares). Por otro lado, y en la medida de lo posible a partir de sus testimonios, hemos procurado detectar la evolución de las relaciones establecidas, en el sentido de que una relación inicialmente caracterizada como "de vinculación" a partir de coincidencias adquiridas, con el tiempo puede transformarse en una de "unión", en función del incremento de la confianza y los intercambios entre los agentes.

\section{Las redes como forma de acceso a recursos: Los casos analizados}

En el caso particular de la producción agropecuaria, la herencia es una de las principales vías a través de las cuales se accede a recursos necesarios para el desarrollo de la actividad (particularmente la tierra) y a nociones técnicoproductivas, ya que comparada con otras actividades, en ella adquieren relevancia central los conocimientos tácitos, no codificados: La profesión del agricultor, aunque hoy en día exige conocimientos "modernos" - en particular en la esfera de la comercialización -, se enraiza en saberes que son fruto de la transmisión por el ejemplo y la palabra. (Kayser, 1990). ${ }^{6}$ Nosotros nos acercaremos a situaciones donde, en ausencia de una transmisión directa por parte de la familia, otros lazos

\footnotetext{
5 Estas definiciones de unión, vinculación y aproximación no deben confundirse con las de Putnam, quien establece una distinción entre el capital social de aproximación, que genera vínculos entre grupos, y el capital social de unión, que crea vínculos intragrupos.

${ }^{6}$ Según Kayser (1991), la cultura técnica del agricultor permanece como un elemento de singularidad y de identidad, que necesariamente imprime su marca al mundo rural. Esto no implica asumir al oficio como inmutable, al contrario, éste permanentemente incorpora nuevos conocimientos, mediante un proceso donde éstos son articulados con los conocimientos preexistentes.
} 
interpersonales pueden ser una vía importante de transmisión de conocimientos y de acceso a diferentes recursos.

La distinta intensidad de los vínculos establecidos, así como el papel que desempeñan en emprendimientos encarados por sujetos que carecen de experiencia como productores independientes, es puesta de manifiesto a partir de algunos casos tomados como ilustrativos, cuya inclusión permite visualizar el carácter dinámico de los lazos, así como la presencia de elementos disfuncionales y ciertamente disruptivos.

Por otra parte, los ejemplos mencionados a continuación revelan que los emprendimientos protagonizados por sectores vulnerables no permanecen en el tiempo sin la inclusión de la familia (o en su reemplazo, otras relaciones sociales basadas en la proximidad), que funcionan como soportes directos e indirectos de su desarrollo. La instalación sin patrimonio o a partir de un capital personal limitado es un proceso largo y progresivo, que muchas veces comienza por el trabajo asalariado y por lo general requiere de ingresos estables que permitan "independizar" al emprendimiento de la subsistencia familiar, al menos durante los primeros años, sean estos ingresos aportados por el propio sujeto que inicia la actividad autónoma o bien por otros miembros familiares.

\section{Estrategias de permanencia sin crecimiento: Basadas en apoyos externos y vinculaciones limitadas}

Marisa integra un hogar de tipo compuesto, con 7 integrantes pertenecientes a diferentes generaciones. ${ }^{7}$ Tiene 37 años, y vive en una localidad pampeana de aproximadamente 12.000 habitantes. En 2004 Marisa inició sus actividades como apicultora. A pesar de poseer una familia numerosa, ésta no participa de la actividad, pero este déficit se vio compensado por la construcción de variadas relaciones sociales de aproximación, de tipo diádico, que facilitaron su inicio y persistencia. Conoció la apicultura por una de sus empleadoras, que la estimuló a acompañarla a visitar sus colmenas y luego la conectó con apoyos provenientes de un programa nacional: “El primer día que fui me encantó y después salió lo del curso...me avisó ella que había un curso, para que así aprendiera, para que el día que ella no estuviera yo siguiera con las colmenas. Yo sin saber que nos iban a dar material, porque me desayuné cuando ya había empezado el curso, y pensaba en ayudarla a ella, pero no quería meterme porque estaba muy ocupada. Después le

\footnotetext{
7 El padre y los dos hermanos trabajan por cuenta propia (en pintura y restauración de muebles), asimismo forman parte del hogar tres sobrinos adolescentes. Ella es empleada doméstica con cierta previsibilidad de ingresos; uno de sus trabajos es en blanco. Todos los miembros familiares tienen estudios primarios completos, excepto los más jóvenes que todavía no los completaron.
} 
dije a la señora que no quería las colmenas.... Pero bueno, que dale que 'agárralas, que las llevamos todas juntas', y me terminé enganchando más." El campo donde ubicar las colmenas también lo consiguió a través de su empleadora.

Un conocido (familiar del dueño del campo donde ubica sus colmenas), le revisa las colmenas cuando ella no puede ir (tiene ubicadas las suyas en el mismo campo); también la ha ayudado a cosechar con su empleado. Es un apicultor consolidado, que posee numerosas colmenas y sala de extracción, y le realiza el servicio de extracción de miel por una suma que Marisa evalúa como inferior a la que le que cobraría a otras personas: "Me dice dame \$20 y ya está, pero porque somos amigos bastante personales...por más que él no quiera yo siempre le digo que lo mínimo que necesite que cuente conmigo. Cuando tiene que ir a ver las colmenas de él y no tiene con quién ir, yo lo acompaño." Es también un canal de información a quien consulta.

Marisa no pertenece a ningún grupo de apicultores. No cree que en la zona haya un lugar en el pueblo donde los apicultores se reúnan, a pesar de que existen muchos dedicados a esta actividad. No participa de ninguna organización ni conoce de su existencia. "Si alguien por ahí me propone, o hay una reunión y está dentro de mis horarios libres voy, no tengo inconveniente. (...) Prefiero que los que me ayuden sean poquitos y que no sea un grupo muy grande".

Dada la escasa cantidad de miel obtenida, la vende fraccionada a vecinos y amigos. Su principal limitante es la falta de tiempo, por esa razón no amplió la cantidad de colmenas que recibió del programa. Durante la época de cosecha va al campo a las 5 de la mañana, y en tres horas debe hacer todo el trabajo. En general hace frente a los insumos necesarios con dinero proveniente de la propia actividad. No se define como apicultora, ya que para ella este carácter lo tienen aquellos que se dedican full-time; no obstante conserva las colmenas "porque si el día de mañana me canso de trabajar y veo que se puede vivir de la apicultura, me dedico a la apicultura".

En contraste, Norberto vive solo en la casa que perteneció a sus padres en un pequeño pueblo rural de menos de 2000 habitantes. Tiene 41 años y estudios primarios completos. Su trayectoria ocupacional consistió en diversas actividades no agrarias inestables (herrería, carpintería, construcción) hasta que consiguió un trabajo en relación de dependencia en la fábrica de quesos de la localidad, donde 
también había trabajado su padre. La fábrica cierra, y pasa a desempeñarse como albañil por cuenta propia y en "changas" diversas. Actualmente trabaja en un emprendimiento hortícola desarrollado en terrenos de una escuela agropecuaria. Menciona antecedentes familiares en horticultura, "venimos de una familia medio quinteros" y expresa que la actividad le gusta, recibiendo capacitaciones específicas en el ámbito escolar.

La huerta tiene una producción diversificada y ocupa $100 \mathrm{~m} 2$ aproximadamente. Se entera de su existencia a través de un ex empleado de la fábrica, que también reside en el pueblo. En un principio ambos efectuaban todas las tareas manualmente, luego la escuela recibe apoyo de diversos programas públicos y privados que le permitieron incorporar tecnología y plantear nuevos emprendimientos. Con su ex compañero de trabajo en la fábrica y actual compañero en la huerta realizan las tareas productivas y reparten la producción, utilizando sus propios vehículos. Dividen el dinero obtenido de la venta por mitades. Norberto se siente involucrado en la comercialización: "Yo voy y hablo, ofrezco. Somos gente conocida." Vende a particulares y a un negocio del pueblo; no obstante, con su "socio" encuentran dificultades para sostener la continuidad en la oferta y ser privilegiados por los comerciantes locales, que se aprovisionan en mercados distantes.

No posee vínculos con otras personas que desarrollen la misma actividad, tampoco con organizaciones. Las relaciones sociales de vinculación refieren a coincidencias adquiridas "tratar de trabajar los dos juntos", pero éstas se ven influenciadas por la relación con la institución escolar. Las dudas técnicas las consultan con una docente, las iniciativas ("ideas") con la directora. El establecimiento les cede el terreno y la maquinaria empleada en la huerta; las semillas son aportadas por el Instituto Nacional de Tecnología Agropecuaria (INTA). La continuidad del emprendimiento Norberto la ve ligada a su colaboración con la escuela; además, ésta financió de alguna manera su participación hasta que la huerta empezara a dar producción: “Vine a hablar con Mónica [directora de la escuela] y bueno... y arreglé con ella hablando y... porque el tema es que quería que trabajara la huerta pero no quería ni cargo ni sueldo. Entonces, 'no' Le digo, 'se me hace muy difícil', le digo. ... hasta que yo siembre y empiece a cosechar necesito 3 o 4 meses. $Y$ yo qué hago? (...) Y bueno, entonces, vieron ellas la posibilidad de qué podían hacer y entonces, me consiguieron como un subsidio, no sé, de 400 pesos por medio día. Trabajando 4 horas todos los días. De lunes a viernes... 'Si es así, sí', le digo."

La perspectiva de tener un ingreso estable opera como un incentivo a continuar ligado al emprendimiento, ya que claramente en este caso existe "una memoria de 
tiempos mejores" y la percepción de lo que constituye un "buen" trabajo (estable y con aportes sociales): "Yo siempre lo que traté de buscar es un trabajo efectivo. Un trabajo de decir "Bueno, yo todos los meses tengo un sueldo." Continúa trabajando como albañil "porque si yo tuviera que trabajar todo el día acá, no lo puedo hacer."

En ambos casos se destaca la importancia de los apoyos externos, que fueron decisivos para el inicio en la actividad. La continuidad en ella parece depender de las relaciones de puente o aproximación establecidas con otros productores más consolidados, o del vínculo con una institución patrocinante (escuela). La priorización de la actividad previa al emprendimiento se traduce en una baja 0 inexistente canalización de recursos a su desarrollo, que no sean los aportados por fuentes externas; asimismo, no se observa el involucramiento de la familia nuclear o extensa como soporte de la actividad encarada.

\section{Estrategias de capitalización: Basadas en relaciones sociales múltiples y la reinversión de excedentes}

Horacio tiene 29 años, estudios secundarios completos, y vive en la misma localidad que Marisa, junto con su abuelo, su mujer y una pequeña hija. Empezó a trabajar de adolescente, ayudaba al padre haciendo leña y "changas" como electricista. Se mudó a otra localidad para realizar estudios terciarios pero al poco tiempo regresó porque no podía sostenerse. Tuvo distintas ocupaciones urbanas y rurales; actualmente trabaja por cuenta propia como electricista y por las noches, como mozo en un bowling. Se inició como apicultor en 1999. "Yo lo había visto a papá que había hecho colmenas y eso. Y después se cansó y las vendió todas... Y después empezamos de nuevo....es un trabajo que te lleva tiempo, pero no tanto. Podés hacer otras cosas...Y a su vez es una plata extra que te entra que a uno no le viene mal. ...era bastante accesible... Yo tenía una plata ahorrada...Entonces, yo digo, antes de tenerla ahorrada la invierto en algo que en el día de mañana me va a dar algo."

Empezó con 17 colmenas, logró ampliarlas a 60, cuando es beneficiado con el apoyo proveniente de un programa nacional, a través del cual obtuvo 20 colmenas, herramientas necesarias para llevar a cabo la actividad y un curso de capacitación (este último, un requisito establecido para acceder al apoyo, lo mismo que la devolución parcial de lo obtenido bajo la forma de una donación a un institución de la comunidad). Actualmente trabaja las colmenas a medias con el padre, durante la época invernal éste se encarga de revisarlas, mientras que en verano se ocupan ambos de la cosecha. 
Su trayectoria en el emprendimiento es exitosa, ya que actualmente posee más de 100 colmenas. Considera que su principal dificultad es conseguir buenos campos, que le permitan obtener buenos rendimientos. La actividad le gusta y "me ha redituado bastante". Su estrategia se basa en reinvertir lo obtenido en ampliar su producción: “Cuidándolas, dedicándoles algo de tiempo, te da plata y por ahí como yo por ahí esa plata no la uso, mayormente, me trato de manejar con lo que hago de trabajo..." Además del hecho de que la actividad no agropecuaria "financia" su desarrollo como apicultor, diversos tipos de relaciones sociales le facilitaron el inicio y posterior permanencia, brindándole acceso a diverso tipo de recursos.

Las relaciones sociales de unión se evidencian en el trabajo "a medias" con el padre y en la ayuda del hermano en los momentos "pico", sin recibir pago alguno, y son también importantes para acceder a los campos donde ubicar las colmenas: uno de ellos es prestado por una tía; el otro, pertenece a la madre de una amiga de la hermana. En un tercer campo, perteneciente a un abuelo y actualmente arrendado, paga un porcentaje de miel por colmena.

Las relaciones sociales de vinculación son fundamentalmente informales. El padre concurre con asiduidad a un aserradero apícola, donde suelen ir otros apicultores del pueblo con tradición en la actividad. "Mayormente se va porque se aprende y se charlan muchas cosas." Asimismo, los proveedores "traen cuentos de otros lugares." En esta instancia se deciden a veces compras conjuntas de insumos; no obstante, reconoce divergencias entre los apicultores. ${ }^{8}$

Horacio no participa de reuniones con sus ex compañeros del curso de apicultura: “Cuando salimos del curso se hicieron 2 grupos. 2 cooperativas, o algo así, las iban a llamar... pero no sé qué pasó. ...Como eran todos chicos nuevos, la mayoría, que recién empezaban a poner... entonces, el profesor propuso eso. Se reunieron ellos. Yo, te soy sincero... no podía ir."

Las relaciones sociales de puente o aproximación se dan con la dueña de la sala de extracción donde su padre trabaja, ya que a través de ella vende su producción a cambio de un porcentaje - tanto él como su padre no están inscriptos como apicultores -. También en ocasiones compra insumos a través de este canal.

Marcelo tiene 42 años, estudios secundarios incompletos y dos hijos en edad

\footnotetext{
8 Este y otros testimonios aluden a la existencia de desacuerdos entre los apicultores vinculados a la forma de manejo de las colmenas (fundamentalmente en lo relativo a la aplicación de antibióticos y la realización de curaciones en forma preventiva), así como en la ubicación de los apiarios (respetando la distancia requerida para no afectar los rendimientos).
} 
escolar. Como el caso anterior, se trasladó a otra localidad con la intención de estudiar pero por razones económicas debió abandonar sus estudios. Su señora es maestra jardinera y posee un empleo estable en relación de dependencia. Vive en casa construida por él en una localidad pampeana de menos de 7000 habitantes. Su familia cultivaba productos de huerta, aunque se dedicaban a actividades no agropecuarias; en su caso, comenzó a trabajar en la gomería de su padre ubicada en un pequeño pueblo y luego en la construcción, primero como peón de albañil y luego en forma independiente, actividad que mantiene, complementando con "changas" como pintor.

Su inicio como apicultor fue de pequeño: "siempre me gustó, terminé la escuela y empecé con apicultura, [las colmenas] las vendí porque no podía." Retoma la actividad en 2003 gracias a un apicultor grande, quien le "dio una mano", regalándole un "núcleo" (enjambre). Trabaja en su emprendimiento los fines de semana y en el horario de la siesta.

Sus redes sociales son diversificadas. Las relaciones sociales de unión se expresan en que su mujer lo ayuda a revisar las colmenas durante los fines de semana, y en que accede al campo donde ubicarlas a través de un vecino; a éste le entrega algo de miel "como una gentileza".

Las relaciones sociales de vinculación incluyen la pertenencia a un grupo, a través del cual accede a actividades de capacitación provistas por el programa PROFAM del INTA, que se basa en esta modalidad de funcionamiento. No obstante, su actividad como albañil le restringe su participación en jornadas de campo. Para emprender otro tipo de acciones "nos ponemos de acuerdo dos o tres apicultores y decimos 'bueno, vamos a hacer esto, lo otro'." Cree, no obstante, que existe envidia vinculada a la cantidad de colmenas. "Hay gente que te ayuda y te da explicaciones y otra que no..."

Marcelo está asociado a la cooperativa de apicultores del lugar, si bien su pertenencia es claramente instrumental: en función de la normativa vigente necesita el número de la sala de extracción para poder vender su producción: “Como pienso llegar a cierto lote de colmenas, a 300, 350, que veo que puedo manejar... Para no estar inscripto, como no tengo obra social, no tengo nada, a través de la cooperativa, porque tiene un número de RENAPA." No participa de las reuniones de la entidad, "reunirse se han reunido, a mí no me han avisado, pero yo sé que se han reunido."

Relaciones sociales de puente pueden detectarse en el apoyo recibido para retomar su actividad productiva, así como en los vínculos establecidos con otros apicultores 
más consolidados que le permiten acceder a recursos necesarios para su actividad: "Favor, favor estoy pidiendo porque no tengo camioneta. Tengo un amigo que me lleva.... Y como tenemos el campo cerca, por ahí hacemos las colmenas de uno y después del otro."

Esta relación posee un contenido diferente de la establecida con otros apicultores grandes, a través de los cuales accedió a herramientas apícolas a cambio de trabajo (todas las que tiene las consiguió por esta vía): “Hay un señor F. que le he hecho trabajos y me ha pagado siempre con, bueno, yo le pongo precio a mi trabajo y el le pone precio a sus herramientas." Este arreglo resulta funcional a ambos: "El con esas herramientas que yo tengo, trabajó 400 colmenas, se agrandó y tuvo que cambiar maquinarias." (...) "Yo he trabajado así, un día, dos días, me dan los materiales. (...) Y no me pagan en efectivo, me pagan para que yo vaya aprendiendo y creciendo o haciendo colmenas."

También estos vínculos le posibilitaron financiar los gastos requeridos para trasladar sus colmenas hacia lugares más distantes: “Me dieron una mano grandísima; tuve la suerte de viajar 3 años al norte a Entre Ríos a trasladar colmenas y hacer todo el período del citrus, a aprovecharlo y se triplica la cantidad. (....) Me llevaban las colmenas mías con ellos (...) No es que me pagan el día, sino que paro con ellos allá, tengo los gastos pagos." Asimismo, valoriza que a través de estos contactos pudo aprender cómo es el manejo de un emprendimiento importante. “Uno trabaja 1200 colmenas, ahí uno tiene una idea de cómo trabajarlas, del grupo [se refiere al grupo Profam a través del cual recibe la capacitación], aprende como curar las colmenas."

La actividad le gusta y la ve como un ingreso complementario "como lo mío no es un cosa segura que tengo."(..) "Las voy manteniendo de mi bolsillo, no tengo ingresos de las colmenas todavía... yo quiero que las colmenas me den para pagarle estudios por lo menos a los chicos." La estrategia se basa en reinvertir lo obtenido para ampliarse, y es posibilitada por el trabajo de ambos cónyuges en otras actividades, aunque considera al ingreso de su esposa como el más importante, ya que en su caso, el mal tiempo le obliga a suspender su trabajo como albañil.

Marcelo llegó en un lapso relativamente corto a tener 200 colmenas, si bien la cantidad disminuyó en función de enfermedades que afectaron a sus abejas.

En estos casos observamos que la experiencia previa en una actividad por cuenta propia relativamente continua, pero donde los ingresos obtenidos son variables, hace que las oscilaciones típicas de la actividad agropecuaria sean vivenciadas de 
manera distinta que cuando el trabajo asalariado ha moldeado la trayectoria ocupacional. Sin embargo, el hecho de desempeñar múltiples ocupaciones restringe la participación en ciertos espacios de sociabilidad que pueden funcionar como instancias de intercambio de conocimientos no codificados.

El inicio en la actividad fue posibilitado por la canalización de ahorros previos. Al existir un objetivo de crecimiento se reinvierte lo obtenido en su ampliación. Esta estrategia se apoya en los ingresos generados por otras actividades a cargo del sujeto $u$ otros miembros de su familia, que garantizan su reproducción a lo largo del tiempo. Desde el punto de vista de las relaciones sociales establecidas, se perciben diferentes tipos de lazos - de unión, de vinculación y de puente -, destacándose los vínculos de tipo diádico, o bien basados en grupos reducidos. La inclusión en instancias más formales (cooperativas) se da en uno de los casos mencionados y adquiere un carácter instrumental, para posibilitar la venta de acuerdo a la normativa vigente.

Los lazos sociales pueden pensarse como un recurso complementario a los aportes provenientes del trabajo familiar - tanto en términos del trabajo propiamente dicho, como de los ingresos generados a través de otras actividades -. Cuando no hay aportes indirectos de otros trabajos que posibilitan durante varios ciclos productivos la reinversión de lo obtenido del emprendimiento el resultado es el estancamiento; de hecho, ésta es la situación de la mayoría de los casos analizados en el marco de la investigación, que no necesariamente muestran escasez de vínculos "útiles".

\section{Asimetría de recursos y vínculos verticales}

En los casos de Marcelo y Marisa encontramos que las relaciones establecidas con apicultores consolidados constituyen una vía de acceso a apoyos para iniciar o retomar la actividad.

La consideración de estos vínculos reafirma que es el contenido de la relación más que los atributos de quienes participan de ella (más precisamente, en términos de acceso a recursos) lo que termina definiendo su carácter "horizontal" o "vertical". En ciertos casos el intercambio se asemeja a una relación laboral precaria, por ejemplo cuando Marcelo expresa la conveniencia para el apicultor que lo contrata de pagar su trabajo con herramientas, ya que éstas dejaron de resultarle útiles para una escala de trabajo mayor. El pago con materiales puede asimismo ser visualizado como un mecanismo desarrollado por éste para evitar el desembolso de dinero, un aspecto importante en las actividades que presentan una lenta rotación 
del capital, como es el caso de la mayoría de las agropecuarias. La condición de precariedad subyacente en intercambios de estas características es resaltada por otra entrevistada al referirse a su hijo: “El estuvo trabajando, trabajaba como empleado, pero... más que nada lo usaban y le pagaban re poco...Le pagaban con material, y tal vez, por ahí, algo de dinero, pero era poco."

En contraste, cuando se realizan trabajos en común - no trabajos "para"- , y hay un sentimiento de confianza, "de contar con el otro", las asimetrías de recursos, si bien son reconocidas, pasan a un segundo plano. De esta manera, eventuales intercambios de trabajo por materiales adquieren otro contenido, o bien los aportes recibidos no son visualizados como una "dádiva" proveniente de alguien mejor posicionado, sino como una "ayuda" que a futuro podrá ser retribuida -aunque en la práctica no lo sea. El hecho de que la distancia social no sea vista como tal usualmente es el resultado de un proceso en el que los vínculos establecidos se van redefiniendo.

Es el caso de Teresa, quien posee un emprendimiento apícola con su hijo, iniciado cuando éste era alumno de una escuela agropecuaria. Al haberse trasladado a otra localidad para continuar sus estudios, ella cuenta con la ayuda de otro apicultor (ex profesor de su escuela) para revisar las colmenas y trasladarlas. También éste le ha "prestado" el campo de un familiar para ubicarlas; la producción es vendida en conjunto. "Nosotros, sacábamos poco... no... con medio tambor vos no podés... Entonces poníamos un resto mío... Por ejemplo: 200 kg. eran de Fabián y 100 kg. eran nuestros y se metían en un solo tambor... Siempre nos arreglamos muy bien con ese tema."

Esta colaboración es compensada con el trabajo del hijo en la cosecha de miel del ex profesor durante las vacaciones de verano. Sin embargo, la relación no es asimilada a la establecida entre un asalariado y un patrón: "Cuando viene mi hijo trabaja con él. Trabaja en el galpón, limpia cuadros... lo ayuda a Fabián en las cosechas... No sé como es el arreglo que ellos tienen, con eso no me meto. Pero él trabaja muchísimo, y Fabián encima le paga, así que es más el trabajo que hace el chico, viste?"

Por lo tanto, un aspecto a profundizar son las motivaciones subyacentes a estos vínculos colaborativos entre agentes que se caracterizan por sus asimetrías de recursos. Como señala Portes (1999), si bien resulta obvio porqué los "receptores" se involucran en estas relaciones, la pregunta clave es porqué sus "benefactores" lo hacen. 


\section{Los límites a la construcción del capital social}

Las relaciones sociales construidas pueden ser funcionales en determinadas instancias, pero presentar limitaciones cuando se las considera desde un punto de vista "meso- sociológico", es decir, el de las vinculaciones establecidas a nivel de la comunidad y su eventual contribución a procesos de desarrollo local. Ello puede ocurrir por que la presencia de fuertes vínculos de unión, basados en la familia nuclear y extensa, indirectamente puede neutralizar la emergencia de otras vinculaciones entre pares a partir de coincidencias adquiridas, e inclusive restringir la participación en asociaciones formales. Es ilustrativo al respecto el siguiente caso, caracterizado por un fuerte entramado basado en la familia extensa.

Con una trayectoria ocupacional fundamentalmente como niñera y empleada doméstica, Nadia se inició en la apicultura gracias a un programa estatal que le aportó capacitación, colmenas y herramientas. La actividad es realizada conjuntamente con el marido, quien previamente había trabajado con un apicultor - ocupación que actualmente mantiene - aunque este vínculo no fue considerado importante para el desarrollo de su actividad. Ello contrasta con la valorización de los aportes recibidos de la familia ampliada, que también se dedica a la apicultura como actividad complementaria. Sus padres les regalaron algunas colmenas con motivo del nacimiento del primer hijo. Actualmente, Nadia y su marido ubican las colmenas en el mismo campo que su cuñado y concurren a revisarlas con la camioneta de la madre, pagando el gasoil; otros dos campos los consiguieron a través de otros miembros de la familia. Utilizan sus instalaciones para extraer la miel "Cosechamos en la sala de ellos, usamos el extractor, todo de ellos". La madre de Nadia la ha ayudado a cosechar cuando a su marido "no le dan los tiempos", pero a su vez, éste intercambia con su padre recursos por trabajo: “Diego hizo las tablitas y mi papá nos dio el remedio, intercambiaron trabajo... después Diego le volvió a cortar las tablas para hacer los techos, y mi papá le volvió a dar remedios, entre ellos se arreglan...Gracias a Dios que está la familia que siempre te da una mano." Estos vínculos también les fueron útiles a la hora de comercializar la producción ya que "cuando empezaron a pedir boleta, mi mamá se inscribió y ya vendían a este hombre de Tandil, y después empezó el tío [que acopia para un exportador] y es como que el tío nos salvó a todos." Si bien el marido tiene relaciones informales con otros apicultores en el galpón donde trabaja, la familia es un canal de información sumamente importante, ya que "no tienen otro tema que no sean las abejas".

Dada la existencia de estos soportes familiares, existe una decisión de no participar en instancias más amplias que probablemente involucrarían costos 
percibidos como innecesarios: “no, porque los que están en la cooperativa...compran todos juntos azúcar, y les sale más barato,....pero como nosotros nos manejamos siempre con mi tío y con mi viejo entonces no..."; "vos trabajas a tu manera y nadie te tiene que venir a decir que tenés que armar o poner las colmenas en este lugar." La existencia de esta organización no le parece importante, sí en cambio agrupar la venta en base a la "red" familiar existente: “Mi tío está con la idea de juntarnos a todos pero no pasa nada... tipo una cooperativa, para vender todos juntos y sacarles buenos precios. Desde ya que él siempre tira para lo que es la familia."

Nadia ha duplicado la cantidad de colmenas recibidas a través de apoyos externos. Como en otros casos que crecieron en la actividad, existió una estrategia de reinversión de lo obtenido ("de lo que es de las abejas no se toca nada, es para agrandarnos o para comprar algo que tenga que ver con eso"). No obstante la funcionalidad de sus vínculos, basados en la familia extensa, parece constituir un impedimento para participar en otros ámbitos, basados en modalidades de funcionamiento distintas a las conocidas. Como expresan Messner y Meyer Stamer (2000), las relaciones de largo plazo, si bien pueden favorecer el desarrollo de orientaciones y visiones comunes, también pueden sustentar prejuicios y resistencias a introducir innovaciones. En el nivel más amplio de la localidad, tales identificaciones sólidas a nivel grupal pueden contribuir a generar fragmentación social (Adler y Woo Kwon, 1999).

Por el contrario, en otras situaciones encontradas las relaciones sociales se vuelven manifiestamente disfuncionales, aunándose a otros rasgos de vulnerabilidad (recursos limitados provenientes de otros trabajos, calificaciones escasas, salud frágil) para dificultar la permanencia de los sujetos en los emprendimientos encarados.

Mabel tiene 45 años, estudios primarios completos. Su hogar se compone de 6 miembros; vive en la periferia de una localidad pampeana de menos de 7000 habitantes. Por lo general trabajó de empleada doméstica; actualmente cuida abuelos cobrando por hora. Inició un emprendimiento de pollos parrilleros en 2005 con apoyo municipal; en ese momento era beneficiaria del Plan Jefes y Jefas de Hogar y concurría a la escuela de adultos como contraprestación: "Yo fui y me anoté. La idea mía era criar terneros, porque yo tengo dos vacas, en ese momento no las tenía, pero mi marido iba a comprar una y yo con el trabajo de sirvienta me 
podía seguir comprando terneritos.(...) y bueno digo, 'si me dan algo más, para mí', viste?, porque yo ya teniendo todo eso, capaz que no tengo nunca más que trabajar. Porque yo tengo problema de hernia de disco." Recibió 600 pollos, bolsas de alimento balanceado y materiales para construir un galpón.

Las redes presentes en su caso son familiares, pero complicaron el desarrollo de su emprendimiento. Debido a un requisito del subsidio, debió conformar un grupo. “Los pelábamos nosotros, bah, yo los pelaba porque al final el emprendimiento ese mío era de tres personas, era mi nuera que vive acá al lado y mi yerno que está en el campo, o sea, yo necesitaba dos personas para que me dieran a mí, no lo quería hacer con otra persona desconocida, porque viste que vos siempre desconfiás (....) Tenía el problema que tenía chanchos acá atrás, entonces los pollos no podían estar cerca de los otros, por el virus y por todo eso. Entonces yo agarré y acá a una cuadra y media vive mi hermano, que es la casa de mi papá, entonces yo le pregunté si lo podía armar ahí al galpón" (...) "Yo puse la mano de obra, y bueno, uno siempre piensa que la familia lo va a ayudar y no, me fue re mal, lo perdí todo." Además, tuvo problemas de "competencia desleal" por parte de vecinos que iniciaron otros emprendimientos similares por la misma época. "Yo tenía los pollos para vender y el hombre aquel de la esquina capaz que iba y decía 'no le comprés a la Mabel, porque los pollos de la Mabel tienen esto, tienen aquello'.

Decide entonces armar otro galpón más precario en el fondo de la casa donde vive, y transferir parte de los pollos a su hija, ya que en su caso obtuvo un empleo cuidando personas mayores, que le aportaba un ingreso bajo aunque fijo. "Y 29 pollos le quedaron y desparejos, porque vos los pollos no los podés dejar...ella tiene un gallinero casero, ella primero me los crió en un galpón con un foquito con la luz."

Dada la situación de vulnerabilidad del hogar, los ingresos obtenidos del emprendimiento fueron destinados en su caso al consumo familiar: "no me ponía a pensar 'tengo que comprar alimento', porque era un sueldo para mí.... Y con ese sueldo me puse el agua, bueno me compré cosas para mi casa. (...) Ahora es el tema, ahora me doy cuenta." A las dificultades para acordar una estrategia conjunta con la familia ampliada y la falta de interés en el tema por parte de la familia nuclear, se sumó su abandono parcial de una actividad que no llegaba a ser visualizada como alternativa generadora de ingresos.

En casos como el analizado, las relaciones sociales aportaron recursos negativos al desarrollo del emprendimiento. No obstante, la presencia de lazos sociales más sólidos y efectivos probablemente no hubiera producido resultados sustancialmente 
diferentes, teniendo en cuenta que las posibles contrapartes presentaban carencias agudas: "Mi vecino de acá al lado que es mi consuegro, agarró y directamente los 600 pollos los hizo percha... ellos lo necesitaban, porque son gente grande."

En estas situaciones de "acumulación de desventajas" el capital social sin duda enfrenta fuertes limitaciones y emergen conflictos en el nivel más cercano. Estudios previos (Moser, 1998; González de la Rocha y Escobar Latapí, 2006) coinciden en señalar que la reciprocidad y ayuda mutua no son inherentes a la vida social; la permanencia del "capital social" no puede darse por garantizada, independientemente de otras variables. Cuando los recursos de los hogares se agotan, los individuos dejan de apoyar a su comunidad y se concentran en su propia supervivencia; el resultado puede ser el aislamiento social, o bien situaciones de competencia y apropiación de recursos.

Integrando los resultados del análisis, encontramos que en sujetos vulnerables que inician una actividad agropecuaria aportando su trabajo personal y un capital limitado, las redes sociales posibilitan el acceso a recursos, que se acrecientan si éstas son diversificadas. No obstante no alcanzan para garantizar un camino de crecimiento, en el sentido de que se requiere una base de pluriactividad personal o familiar, que genere recursos monetarios ya sea para iniciarlas y fundamentalmente, para poder consolidarse en ellas, y también para poder sostener el involucramiento en relaciones sociales. No se encontraron situaciones donde el emprendimiento se hubiera transformado en la única fuente de ingresos, aunque en algunos casos representa el ingreso principal y a su vez ha generado actividades conexas (como el acopio de la producción y la venta de insumos). Cuando ello ocurre, las relaciones sociales basadas en la familia extensa, pasan a desempeñar el papel de "resguardo" ante dificultades que pudieran surgir del emprendimiento. De esta manera, el papel jugado por las relaciones sociales es dinámico, cumpliendo funciones diferentes de acuerdo a la evolución del emprendimiento y del contexto en que éste se inserta.

\section{Las redes sociales como mecanismo de construcción identitaria}

Los vínculos sociales no constituyen meros canales de acceso y/o distribución de recursos, aún en los grupos más pobres de la sociedad. Como indica uno de los trabajos mencionados (Robison y otros, 2003), todos los intercambios personalizados incluyen componentes de índole emocional, que inclusive pueden modificar el valor de los bienes intercambiados.

Desde esta perspectiva, las redes sociales también pueden ser visualizadas como mecanismos de construcción de representaciones e identidad. Los aportes de Bourdieu resultan un clásico en este sentido, cuando indica que "el intercambio 
transforma las cosas intercambiadas en signos de reconocimiento, y a través del reconocimiento mutuo y el reconocimiento de la pertenencia al grupo que él implica, produce "el grupo" y determina al mismo tiempo los límites del grupo"-. En la experiencia identitaria intervienen aspectos objetivos y subjetivos, una situación social y una historia personal, pero también la red de relaciones, en donde el lugar propio se determina en relación al otro y en contraposición a él. Entonces, reflexionar acerca del contenido de las interacciones, preguntarnos por aquellas otras que pudiendo estar presentes no lo están, nos permite entender en qué medida o desde qué punto de vista, las redes aportan a los procesos de construcción identitaria. Particularmente, si estos procesos implican una deconstrucción de identidades previas.

Una mirada transversal a los casos permite reconstruir los tipos de relaciones presentes en estos sujetos vulnerables que recientemente han iniciado actividades agropecuarias, así como indagar su pertenencia a instancias más formales de asociación. Tal análisis muestra la preeminencia de los vínculos diádicos o con grupos reducidos, como también cierta dificultad para establecer relaciones sociales "de vinculación", a partir de coincidencias adquiridas, con otros sujetos que presentan características similares y se encuentran en el mismo estadio de desarrollo, especialmente cuando no existen mediaciones externas.

Es decir, cuando la conformación de grupos constituye un requisito establecido por programas estatales para poder acceder a apoyos financieros, tienden a conformarse asociaciones ad-hoc, de corta vida, que no actúan como cimientos colectivos. La pertenencia a organizaciones económicas más formalizadas (cooperativas) también suele verse inducida por fuerzas externas, como los requerimientos establecidos por la normativa para poder comercializar la producción "en blanco".

Así, en gran parte de los casos la pertenencia actual a las mismas (o la evaluación de su conveniencia) se sustenta en criterios instrumentales; la adscripción se basa en el cálculo racional (Portes, 1999). ${ }^{9}$ Los siguientes testimonios de dos apicultores son ilustrativos al respecto:

“No es lo mismo un apicultor suelto que un grupo, una asociación, tiene más respaldo del gobierno, más posibilidad en hacer una sala de extracción habilitada o cosas así, las cosas en grupo son más fáciles."

“- Vos sos socio de la cooperativa?

\footnotetext{
${ }^{9}$ No obstante, la índole de las expectativas subyacentes a la integración de estas entidades cooperativas puede no ser una característica propia de estos "nuevos" productores, sino estar reflejando procesos más generales que afectan a estas organizaciones, "en tiempos donde el diálogo está más orientado a lo mercantil, lo utilitario, y en muchos casos lo individual" (Carricart y Albaladejo, 2005: 63).
} 
- Soy socio.

- Por qué te hiciste socio?

- Porque para lo único que te sirve la cooperativa es para tener el número de sala." [ de extracción]

La triangulación entre las diferentes entrevistas realizadas a microemprendedores sugieren por otro lado que estas entidades expresan, en sus mecanismos de funcionamiento, las diferencias entre aquellos que han iniciado la actividad a partir de un capital limitado y los ya "instalados" - que por lo general acceden a mayores recursos -.

“Acá hay una cooperativa pero tiene muchas cosas que no me convencen... el tema de la venta que no me cierra ....ellos cosechan en otra sala, manejan un protocolo, trabajo igual con ese protocolo, pero cuando van a cosechar he visto que hay muchos problemas, como por ejemplo manejan la sala [de extracción] y te atrasan. Te dicen 'vení mañana' y vas y te dicen 'no vení el viernes', y en todo eso uno pierde kilos de miel...."

\begin{abstract}
“Hay siempre caciques, están los apicultores viejos y ellos tienen cierta potestad sobre nosotros, y no me gusta ese tema....limpian ahí... O sea, 'limpiar' es ir a sacar la miel. Y nosotros no podemos, porque los equipos eran de ellos. [La extracción] sería muy importante para nosotros, porque ahora te piden sala habilitada y todo, y sacar ahí... Por ejemplo, nosotros no tenemos llave, los grandes sí.... Un detalle importante."
\end{abstract}

“- Y ustedes son socios de la cooperativa o no?

- Ahora sí. Nos hicimos socios, porque arrancó el año pasado y dicen que van a... Ahora va a cambiar la comisión y vamos a tener un espacio el grupo, porque nosotros estamos formando un grupo... un grupo de pequeños apicultores, hace ya dos años y tratamos de ayudarnos entre nosotros y nos llevamos bien... Pero por ejemplo, yo me acuerdo antes, cuando yo recién empezaba, y yo iba a preguntar: ' $y$, bueno y ahora... que te parece a vos, para curar... qué usamos, que es lo que estás usando?...' 'Y... yo le puse 'la tablita', que sé yo'... Y le preguntabas al otro y te decía: 'no, eso no da resultado, yo le puse otra cosa...' y capaz que él también le ponía la tablita. No te dan, viste?

c- Quiénes, los apicultores grandes?

m- Los grandes! Los grandes no... jamás... Fueron invitados siempre al grupo, por ejemplo cuando se hacían reuniones en el Municipio, que venía gente del INTA, se invitaba a todos. Jamás fue uno de ellos, de los grandes que hay acá... Que son... 1, 2, 3... 4, que te hablo que el más chico debe tener 700 colmenas. Y no se los ve jamás! Cada uno por su lado!

c- $Y$ esos están en la cooperativa...?

m- No, esos no están, cada uno tiene sala de extracción propia. Los que están en la cooperativa son también medianamente chicos, pero que no... tampoco quieren estar en el grupo... son de 200,300 colmenas..."

Entonces, en estas pequeñas localidades pampeanas, a pesar de (o a raíz de) el conocimiento mutuo, los espacios de sociabilidad pueden resultar segmentados, solidificando, de alguna manera, las diferencias de clase existentes entre los 
actores. Asimismo, el "capital social" de los productores medianos - que conforman la membresía típica de las organizaciones cooperativas - presenta ciertas dificultades para ampliarse, e incluir a otros agentes sociales de menor escala productiva y de conformación más reciente. Este es un aspecto decisivo para la generación de procesos de desarrollo local, por la condición "bisagra" de estos productores entre diferentes sectores.

Si bien puede pensarse que el clivaje en materia organizativa traduce el proceso de diferenciación que experimenta la apicultura como actividad (Murmis y Feldman, 2003), si se considera al conjunto de los casos, que desarrollan diferentes actividades productivas, se percibe un patrón de "estamentización" en el plano asociativo. También la escasa conexión existente entre quienes encaran emprendimientos en pequeña escala y las organizaciones corporativas “tradicionales", presentes desde hace tiempo en las localidades estudiadas.

"Estos días estuvimos hablando con una cooperativa que se ha formado de apicultores, hay muchos. Es un negocio que también nos interesa, y es un negocio, un emprendimiento, que estaría funcionando (....) Me dijeron 'nosotros nos vamos a asociar a la Sociedad Rural porque tenemos interés en ir creciendo y en la conexión con productores (...) Lo que es emprendimiento nos interesa, para darles el apoyo que podemos, porque no somos una entidad que puede facilitar créditos ni nada, pero si todo el apoyo que podemos y las conexiones."

Este testimonio, perteneciente al presidente de la Sociedad Rural de una de las localidades, donde la actividad presenta cierto dinamismo - por la cantidad de apicultores y la importancia de los servicios conexos - muestra que es muy reciente la consideración del sector como "de interés" por parte de la entidad que lidera. El siguiente testimonio, originado en el presidente de la cooperativa de apicultores en otra de las localidades, es en cambio revelador de las representaciones existentes en los apicultores sobre el sector productor "tradicional" y sus organizaciones, y de cómo dicha percepción contribuye a construir la propia identidad (como "afirmación" y “como contraposición"). En este caso se percibe la necesidad de generar una instancia independiente de organización que complemente la ya lograda en lo económico, más que de participar en organizaciones preexistentes.

“- Desde el punto de vista político e institucional nos faltaría una asociación apícola que nos represente en los aspectos políticos, [la cooperativa] nos representa en los aspectos económicos. (...)

- Y la Sociedad Rural no representa al sector apicultor?

- No, no.

- Ustedes tampoco se han acercado.

- La Sociedad Rural representa lo que tiene que ver con el agro y fundamentalmente la carne y el cereal. Te diría que casi ni siquiera el campo. Tampoco nos hemos acercado nosotros, es cierto. 
- Sobre todo porque ustedes tienen relación con los propietarios de campos.

- Sí, pero nosotros somos chiquitos, es como que... nos consideran así. (...)

Se percibe, es como que nunca te convocan cuando se arma la comisión o la renovación de la comisión de la Sociedad Rural."

La situación en materia organizativa parece recordar lo señalado por Lomnitz (2003), en el sentido de que los sectores vulnerables participan en forma reducida en asociaciones, ya que a diferencia de los entramados informales, éstas no desempeñan ninguna función para su supervivencia.

Desde otro punto de vista, la limitada pertenencia a las organizaciones de representación de intereses preexistentes, así como la presencia de membresías de segunda clase en las organizaciones económicas - que implican menores derechos-, limita en nuestra opinión el posible aporte de estas entidades en la construcción de una "nueva" identidad de productor, reforzando condiciones más "objetivas" que operan en la misma dirección - los limitados ingresos derivados de la "nueva" actividad productiva, entre otros aspectos -.

\section{Reflexiones finales}

El análisis de las redes sociales en las que participan sujetos sociales vulnerables que iniciaron actividades agropecuarias en pequeña escala mostró la relevancia del componente relacional como "llave" de acceso a recursos, especialmente cuando éste incluye diferentes tipos de vínculos. Pero tales recursos complementan, no sustituyen, los derivados de contactos con fuentes institucionales o programas y el rol de otros ingresos familiares que son canalizados hacia la nueva actividad o bien la independizan del sustento familiar, aspecto que se revela como el punto central de las estrategias exitosas de permanencia y capitalización. Así el soporte relacional más próximo representado por la familia pasa a primer plano, si bien la presentación de "contraejemplos", encontrados en el transcurso de la investigación, permitió visualizar situaciones problemáticas en este nivel (indudablemente asociadas a la escasez crónica de recursos). También nos permitió plantear el interrogante de si lazos primarios efectivos a escala "micro" pueden resultar limitantes en el nivel "meso" de las localidades estudiadas.

Salvo casos excepcionales, la nueva actividad no logra convertirse en el ingreso principal de los hogares. Frente a "obstáculos" difíciles de sortear para el inicio de actividades agropecuarias (fundamentalmente, la carencia de tierra), se despliegan estrategias creativas como el acceso a campos de conocidos, la puesta en producción de predios pertenecientes a instituciones escolares, el aprovechamiento de galpones o el terreno del "fondo" de la casa para pequeños emprendimientos. Pero esta diversidad de soluciones no puede convertirse en esquemas fácilmente 
replicables, ni supera con facilidad dos rasgos propios de las actividades agropecuarias, que impactan fuertemente en los ingresos: la estacionalidad, atada al ciclo biológico de las producciones, y la exigencia de una escala mínima, con tendencia a incrementarse, para que éstas resulten rentables. Este último aspecto se manifiesta aún en aquellas que han sido elegidas debido a sus bajos requerimientos de acceso. Frente a esta situación, la dinamización de algunas economías locales, en un contexto de demanda creciente de alimentos, no llega a convertirse en una oportunidad factible de ser aprovechada por grupos poblacionales con recursos limitados.

La índole de la aproximación metodológica efectuada, con énfasis en técnicas cualitativas, reveló que el carácter de las relaciones establecidas surge tanto de la consideración de su cercanía e intensidad como de los atributos personales de quienes las entablan: asimetrías de recursos pueden expresar tanto relaciones laborales precarias - "funcionales" para ambas partes, si bien desde diferentes puntos de vista - como también la presencia de ayudas entre personas que comparten denominadores comunes. Las motivaciones subyacentes al intercambio constituyen un aspecto a profundizar en estos casos.

Contrariamente a lo que en principio pudiera suponerse, en los ámbitos acotados de estas pequeñas localidades pampeanas las relaciones que implican vinculación entre pares a partir de coincidencias adquiridas parecen ser las más difíciles de establecer. Este es un punto importante a considerar por los programas de apoyo al sector, ya que muchos de ellos diseñan sus estrategias partiendo de la premisa de que el capital social se puede (y debe) crear.

El carácter informal y espontáneo de los vínculos encontrados por el estudio contrasta con los mecanismos operacionales pautados por los programas, que tienden a forzar la asociación ad-hoc de los solicitantes como prerrequisito para acceder a determinados apoyos, estrategia que parece no sustentarse en el mediano plazo. A ello se agrega que con frecuencia éstos toman su intervención como fundacional, desconociendo las redes y trayectorias asociativas preexistentes, a pesar de que éstas son decisivas a la hora de explicar los resultados (Rodríguez Bilella, 2005). Las evidencias indican que es importante el mapeo de los vínculos previos - y especialmente los intercambios entre agentes heterogéneos- , así como la promoción de ámbitos de conexión no formal (y quizá no sectorial) en los cuales se socialicen saberes. El asociativismo en su expresión formalizada debiera ser considerado un punto de llegada, más que un punto de partida.

\section{Bibliografía}


Adler, Paul y S. Kwon (1999). "Social capital: the good, the bad, and the ugly", mimeo.

Bayón, María Cristina (2006). “Precariedad social en México y Argentina: tendencias, expresiones y trayectorias nacionales". Revista de la CEPAL, No.88, abril.

Carricart, Pedro y C. Albaladejo (2005). "Reflexiones críticas sobre los espacios emergentes: las cooperativas agropecuarias y los espacios rurales en la región pampeana argentina. Un estudio de caso en tres Arroyos, provincia de Buenos Aires" en Roberto Benencia y Flood, C. (coord.), Trayectorias y contextos. Organizaciones rurales en la Argentina de los noventa. Buenos Aires: CEDERUEditorial La Colmena, pp. 49-88.

De Ferranti, David, G. Perry, W. Foster, D. Lederman y A. Valdés (2005). Beyond the city. The Rural Contribution to Development. Washington: The World Bank.

González de la Rocha, Mercedes y A. Escobar Latapí (2006). “Familia, trabajo y sociedad: el caso de México", en Enrique de la Garza (coord.), Teorías sociales y estudios del trabajo: Nuevos enfoques. México: Anthropos-UNAM, pp. 161-182.

Granovetter, Mark (1983). "The strength of weak ties: A network theory revisited", Sociological Theory, Vol. 1, pp. 201-233.

Kayser, Bernard (1990). La renaissance rurale. Paris: Bernard Colin.

Lomnitz, Larissa (2003). Cómo sobreviven los marginados, México: Siglo XXI Editores. 15 Edición.

Messner, Dirk y Meyer Stamer, J. (2000). Governance and networks. Tools to study the dynamics of clusters and global value chains, Documento preparado para el Proyecto IDS/INEF "The impact of global and local governance on industrial upgrading", Duisburg.

Murmis, Miguel (2003). "Cuestión social y lazos sociales" en Mónica Bendini, Cavalcanti, J; Murmis, M; Tsakoumagkos, P. (comps.), El campo en la sociología actual: Una perspectiva latinoamericana. Buenos Aires: La Colmena, pp.53-76.

Murmis, Miguel y Feldman, S. (2003). “Persistencia de la pequeña producción mercantil en un pueblo rural: factores favorables y factores limitantes, ¿situación excepcional o situación generalizable?, Revista Interdiscisplinaria de Estudios Agrarios No. 19, segundo semestre, pp. 73-94.

Portes, Alejandro (1999). “Capital social: sus orígenes y aplicaciones en la sociología moderna", Jorge Carpio y Novacovsky. I. (comps.), De igual a igual. El desafío del Estado ante los nuevos problemas sociales. Buenos Aires: Ed. Fondo de Cultura Económica, pp. 243-266.

Rodríguez Bilella, Pablo (2005). "Trayectorias asociativas en el marco de programas de desarrollo rural: un análisis desde los actores" en Roberto Benencia y Flood C. (coord.), Trayectorias y contextos. Organizaciones rurales en la Argentina de los noventa, Buenos Aires: CEDERU- Editorial La Colmena, pp. 243-269.

Robison, Lindon, Siles, M. y Schmid. A. (2003). "El capital social y la reducción de lapo breza: hacia un paradigma maduro", en Atria Raúl, Siles, M., Arraigada, I., Robison, L.y Whiteford, S. (comps)., (op.cit.), pp. 51-114.

Woolcock, Michael (2001). La importancia del capital social para comprender los resultados económicos y sociales, mimeo. 


\begin{tabular}{|c|c|c|c|c|}
\hline & Rauch & $\begin{array}{l}\text { General } \\
\text { Pinto }\end{array}$ & $\begin{array}{l}\text { Florentino } \\
\text { Ameghino }\end{array}$ & Tres Lomas \\
\hline Superficie del partido (km2) & 4351,26 & 2540,3 & 1808,90 & 1262,45 \\
\hline Población total (2001) & 14434 & 11129 & 8171 & 7439 \\
\hline \% Población rural & 20 & 45 & 24 & 10 \\
\hline Densidad (hab/km2) & 3,31 & 4,38 & 4,51 & 5,89 \\
\hline $\begin{array}{l}\text { \% de asalariados que no le } \\
\text { descuentan o aportan jubilación } \\
\text { (2001) }\end{array}$ & 40 & 39 & 42 & 42 \\
\hline $\begin{array}{l}\text { \% Población desocupada } \\
(2001)\end{array}$ & 9 & 11 & 11 & 11 \\
\hline $\begin{array}{l}\% \text { de mano de obra ocupada en } \\
\text { actividades primarias (2001) }\end{array}$ & 25 & 28 & 26 & 26 \\
\hline $\begin{array}{l}\% \text { de mano de obra ocupada en } \\
\text { actividades secundarias (2001) }\end{array}$ & 14 & 11 & 12 & 10 \\
\hline $\begin{array}{l}\% \text { de mano de obra ocupada en } \\
\text { actividades terciarias (2001) }\end{array}$ & 61 & 60 & 63 & 64 \\
\hline $\begin{array}{l}\text { Cantidad de explotaciones } \\
\text { agropecuarias - EAPS- (2002) }\end{array}$ & 844 & 362 & 182 & 285 \\
\hline \% pequeños productores (2002) & 67 & 43 & 35 & 70 \\
\hline $\begin{array}{l}\text { Superficie promedio de las EAPs } \\
(2002)\end{array}$ & 425 & 660 & 890 & 385 \\
\hline $\begin{array}{l}\% \text { de cereales y oleaginosas sobre } \\
\text { sup. implantada en 1ra y } 2 \text { da (2002) }\end{array}$ & 22 & 69 & 53 & 34 \\
\hline Cabezas de bovinos (2002) & 274635 & 168213 & 150564 & 109548 \\
\hline Tambos instalados (2002) & 14 & 129 & 48 & 35 \\
\hline $\begin{array}{l}\text { \% agricultura (maíz, trigo, girasol y } \\
\text { soja) sobre valor bruto de producción } \\
\text { (VBP) agrícola (1988) }\end{array}$ & 6,37 & 38,25 & $*$ & 11,92 \\
\hline $\begin{array}{l}\text { \% ganadería sobre VBP agrícola } \\
\text { (1988) }\end{array}$ & 93,63 & 61,75 & $*$ & 88,08 \\
\hline $\begin{array}{l}\text { Superficie con cereales y oleaginosas } \\
\text { en 1ra y } 2 \mathrm{da}(2002)\end{array}$ & 7362 & 101030 & 35359 & 24887 \\
\hline $\begin{array}{l}\text { Superficie con } 4 \text { principales cereales y } \\
\text { oleaginosas }(2005 / 06)\end{array}$ & 19900 & 72600 & 58000 & 43300 \\
\hline $\begin{array}{l}\text { Valor de la hectárea } \\
(2002)\end{array}$ & 300 a 400 u\$s & $\begin{array}{r}800 \text { a } 1500 \\
\text { u\$s }\end{array}$ & 700 a 1000 u\$s & 300 a 700 u\$s \\
\hline Valor de la hectárea (2006) & $\begin{array}{r}850 \text { a } 1100 \\
\text { u\$s }\end{array}$ & $\begin{array}{r}2500 \text { a } 3800 \\
u \$ s\end{array}$ & $\begin{array}{r}2500 \text { a } 3800 \\
\text { u\$s }\end{array}$ & $\begin{array}{r}1800 \text { a } 2600 \\
\text { u\$s }\end{array}$ \\
\hline
\end{tabular}

Cuadro 1. Características de los partidos estudiados.

Fuente: Elaboración propia en base a datos del Censo Nacional Agropecuario 2002 y del Censo de Población, Viviendas y Hogares 2001. Datos referidos a pequeños productores: Obschatko, E., M. Foti y M. Román (2006). Datos referidos al Valor Bruto de producción (VBP): Barsky, 1997. Datos de valor de la hectárea y de superficie implantada en 2005/06: Ministerio de Asuntos Agrarios de la provincia de Buenos Aires. 


\begin{tabular}{|c|c|c|c|}
\hline \multirow[t]{2}{*}{ Recursos } & \multicolumn{2}{|r|}{ Vínculos informales } & \multirow{2}{*}{$\begin{array}{c}\text { Pertenencia a asociaciones } \\
\text { económicas y/o organizaciones } \\
\text { de representación de intereses }\end{array}$} \\
\hline & Simples & Múltiples & \\
\hline Externos & $\begin{array}{l}\text { 1: Relaciones de puente. } \\
\text { No aporta otros recursos. } \\
\text { 2: Relaciones de puente. } \\
\text { No aporta otros recursos. } \\
\text { 3: Relaciones de puente, } \\
\text { Aporta mínimos recursos } \\
\text { propios. } \\
\text { 4: Relaciones de puente. } \\
\text { Relaciones de unión y } \\
\text { aproximación negativas. No } \\
\text { aporta recursos propios al } \\
\text { emprendimiento. }\end{array}$ & $\begin{array}{l}\text { 5: Los tres tipos de vínculos, en poca proporción e } \\
\text { intensidad. } \\
\text { En un emprendimiento previo aportó recursos propios; } \\
\text { en el actual, escasa inversión de otros recursos fuera de } \\
\text { los recibidos. } \\
\text { 6: Relaciones de puente, de vinculación y de unión. En } \\
\text { un emprendimiento previo aportó recursos propios; en el } \\
\text { actual no aporta otros recursos. } \\
\text { 7: Relaciones de puente y de vinculación. No aporta } \\
\text { otros recursos. } \\
\text { 8: Ídem anterior. } \\
\text { 9: Relaciones de puente y débiles relaciones de } \\
\text { vinculación. Aporta mínimos recursos propios. } \\
\text { 10: Relaciones de puente. } \\
\text { No aporta recursos fuera de los recibidos }\end{array}$ & $\begin{array}{l}\text { 1: No } \\
\text { 2: No } \\
\text { 3: No } \\
\text { 4: No } \\
\text { 5: Inicialmente perteneció a } \\
\text { una cooperativa } \\
\text { (pertenencia instrumental) } \\
\text { 6: Pertenece a una } \\
\text { cooperativa (pertenencia } \\
\text { instrumental) } \\
\text { 7: No } \\
\text { 8: No } \\
\text { 9: No } \\
\text { 10: No }\end{array}$ \\
\hline $\begin{array}{ll}\text { Propios } & 0 \\
\text { propios } & y \\
\text { externos } & \end{array}$ & $\begin{array}{l}\text { 11: Relaciones de unión. } \\
\text { Aporta recursos propios } \\
\text { además de los obtenidos. }\end{array}$ & $\begin{array}{l}\text { 12: Relaciones de unión, vinculación y de puente. Aporta } \\
\text { recursos propios además de los externos. } \\
\text { 13: Relaciones de unión y vinculación. Recursos propios } \\
\text { además de los obtenidos. } \\
\text { 14: Relaciones de unión, vinculación y puente. Aporta } \\
\text { recursos propios además de los recibidos. } \\
\text { 15: Relaciones de unión, vinculación y de puente. Aporta } \\
\text { recursos propios además de los recibidos. } \\
\text { 16: Relaciones de unión y de puente. Aportes propios } \\
\text { además de los recibidos. } \\
\text { 17: Relaciones de unión, de vinculación y de puente. } \\
\text { Aportes únicamente propios. } \\
\text { 18: Relaciones de unión y de puente. Aportes propios } \\
\text { además de los recibidos. } \\
\text { 19: Relaciones de unión, vinculación y de puente. Aporta } \\
\text { recursos propios además de los recibidos. } \\
\text { 20: Relaciones de unión, vinculación y puente. Aportes } \\
\text { propios además de los recibidos }\end{array}$ & $\begin{array}{l}\text { 11: No } \\
\text { 12: No } \\
\text { 13: Pertenece a una } \\
\text { cooperativa. } \\
\text { 14: No. } \\
\text { 15: No } \\
\text { 16: No } \\
\text { 17: Pertenece a una } \\
\text { cooperativa (pertenencia } \\
\text { instrumental) } \\
\text { 18: Pertenece a una } \\
\text { cooperativa (pertenencia } \\
\text { instrumental) } \\
\text { 19: Pertenece a una } \\
\text { cooperativa (pertenencia } \\
\text { instrumental) } \\
\text { 20: Inicialmente perteneció a } \\
\text { una cooperativa (pertenencia } \\
\text { instrumental) }\end{array}$ \\
\hline
\end{tabular}

Cuadro 2. Sistematización de los casos analizados *

* El numeral corresponde a la identificación del caso relevado. 